\title{
Estudos para um diagnóstico quali-quantitativo em bacias experimentais - Estudo de Caso: Bacia do rio Piabanha
}

\author{
Amanda Morais ${ }^{1}$ \\ Mariana Dias Villas-Boas ${ }^{1}$ \\ Anderson Oliveira Bastos ${ }^{1}$ \\ Achiles Eduardo Guerra de Castro Monteiro ${ }^{1}$ \\ Ligia Maria Nascimento de Araújo ${ }^{2}$ \\ ${ }^{1}$ CPRM - Companhia de Pesquisa de Recursos Minerais \\ Avenida Pasteur, 404 - Urca - CEP: 22290-240 \\ amandamorais@rj.cprm.gov.br; marianadvb@rj.cprm.gov.br; abastos@rj.cprm.gov.br; \\ achiles@rj.cprm.gov.br \\ ${ }^{2}$ INEA - Instituto Estadual do Ambiente \\ Rua Fonseca Teles 121, Campo de São Cristóvão - Rio de Janeiro -RJ \\ ligiamna@inea.rj.gov.br
}

\begin{abstract}
This paper presents a preliminary analysis of water quantity and quality data in the Piabanha's river basin in the Project "EIBEX-I", through the activities undertaken directly by CPRM team. These activities aim to assess the state of its water resources by obtaining a data series that in the future may be used for many studies such as hydrological modeling, stream-flow regionalization, etc.. Initially, the quantitative aspect was prioritized to obtain time series of water discharge and level and rainfall. About water quality, the results show a great domestic sewage contamination in the urban area and, in general, less metal contamination in the basin.
\end{abstract}

Palavras-chave: water quality, qualidade de água, bacias representativas, bacias experimentais

\section{Introdução}

Este trabalho apresenta uma avaliação preliminar dos resultados obtidos para os dados de quantidade e qualidade de água da bacia do rio Piabanha, no âmbito do Projeto "EIBEX-I Estudos Integrados de Bacias Experimentais - Parametrização Hidrológica na Gestão de Recursos Hídricos das Bacias da Região Serrana do Rio de Janeiro”.

No futuro, a continuidade na obtenção destes dados permitirá, dentre outras aplicações, a utilização de modelos hidrológicos que apoiarão a gestão de recursos hídricos na concessão de outorgas de direitos de uso da água - com a melhoria dos métodos de regionalização hidrológica, na previsão de cheias e no controle da poluição hídrica na bacia.

O "Projeto EIBEX-I - Estudos Integrados de Bacias Experimentais - Parametrização Hidrológica na Gestão de Recursos Hídricos das Bacias da Região Serrana do Rio de Janeiro” que teve início no ano de 2006, é financiado pelo MCT/FINEP/CT-HIDRO e recebe apoio financeiro da CPRM - Companhia de Pesquisa de Recursos Minerais, atualmente, através do projeto institucional "Estudos Integrados em Bacias Representativa e Experimentais - Região Serrana - RJ”. A finalidade deste projeto institucional é contribuir com a complementação de recursos necessários a despesas correntes de modo a garantir as instalações e a operação dos equipamentos bem como a continuidade do projeto. Participam ainda do projeto diversas outras instituições: INEA-RJ, IGEO-UFRJ, CATO-UERJ, COPPE-UFRJ.

O Projeto tem como objetivo avaliar o comportamento hidrológico em região com bioma natural Mata Atlântica, e em áreas de ocupação agrícola e urbanizada, utilizando modelos de simulação de sistemas hídricos, de avaliação de processos erosivos, carga de sedimentos e poluição causada por fontes difusas (Araújo et al (2007). 
Para isso houve a implantação de uma bacia representativa e três experimentais e a instalação de uma rede de monitoramento inicialmente composta de nove registradores de chuva e nível d’água dos rios, quatro registradores de chuva, um lisímetro, uma estação meteorológica padrão, uma estação de medição de fluxos superficiais e umidade do solo, dez piezômetros e dez infiltrômetros, serão monitoradas áreas de variadas magnitudes de forma a possibilitar o estudo dos processos hidrológicos em variadas escalas (Araújo et al (2007).

Este artigo tem como foco a apresentação das atividades desenvolvidas diretamente pela equipe da CPRM relacionadas ao levantamento de dados de quantidade e qualidade de água. Tais atividades têm como objetivo o diagnóstico da situação dos recursos hídricos da bacia através da obtenção de uma série histórica de dados que no futuro poderá ser utilizada para diversos estudos como modelagem hidrológica, regionalização de vazões, etc.

\section{Caracterização da Área de Estudo}

O rio Piabanha é afluente pela margem direita do rio Paraíba do Sul e sua bacia ocupa uma área de aproximadamente $2.050 \mathrm{~km}^{2}$, a maior parte inserida na Região Serrana do Estado do Rio de Janeiro. Seus principais afluentes são os rios Fagundes, pela margem esquerda, e rios Paquequer/Preto, pela margem direita. É composta pelos municípios de Areal, Paraíba do Sul, Paty do Alferes, Petrópolis, São José do Vale do Rio Preto, Teresópolis e Três Rios com população total de 590.000 habitantes (Araújo et al (2007)). A Figura 1 apresenta a localização da bacia do rio Piabanha em relação a do rio Paraíba do Sul.

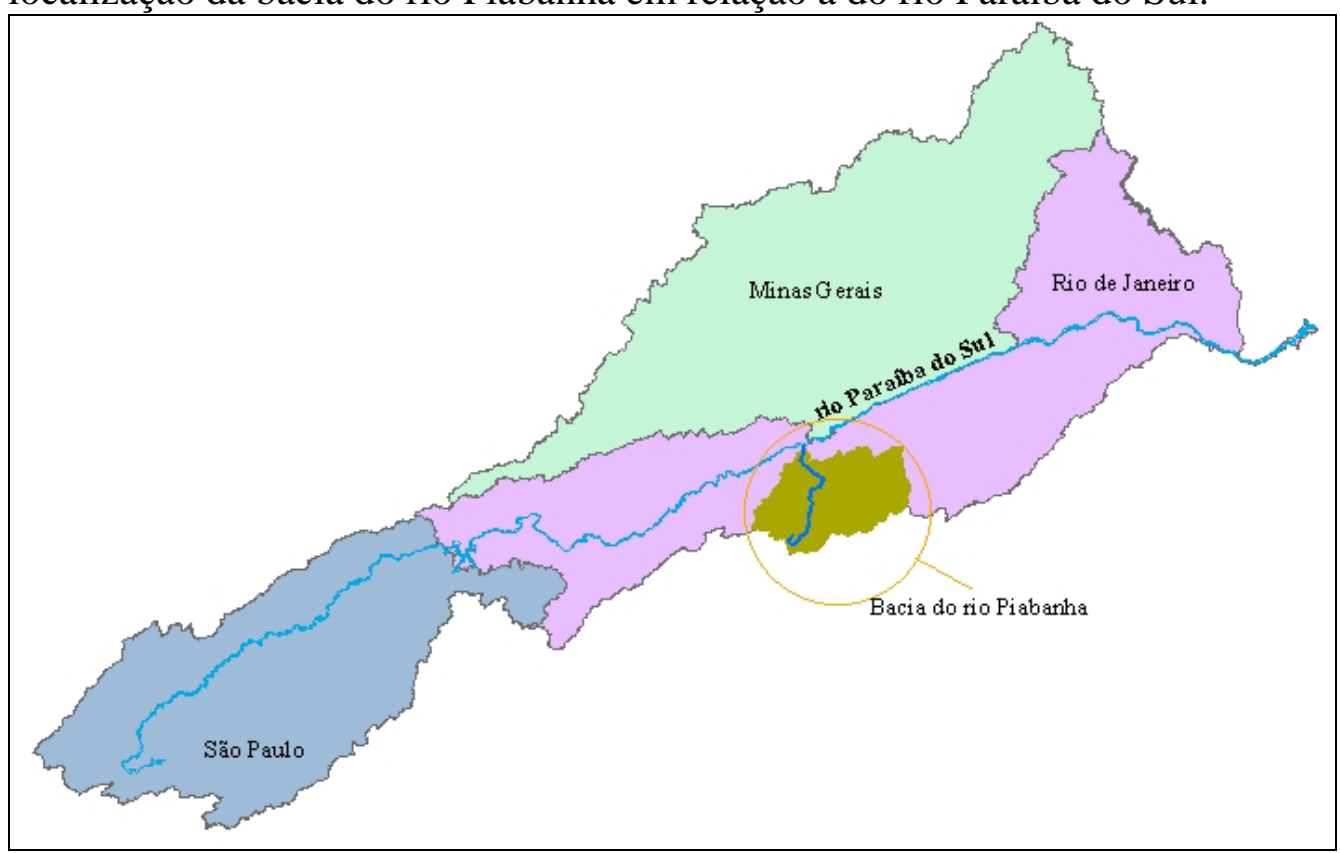

Figura 1. Bacia do rio Paraíba do Sul com destaque para o rio Piabanha.

A área estudada, devido à proximidade com a cidade do Rio de Janeiro, foi induzida a um crescimento urbano acentuado e inadequado para as suas condições ambientais.

A região apresenta problemas graves de erosão das encostas, proporcionados em parte pela ocupação irregular, além de inundação na calha dos rios e qualidade da água deteriorada pelo lançamento de esgotos in natura. O tratamento dos esgotos é precário e as vazões naturais dos rios são muito baixas para a diluição das cargas lançadas, resultando em altos índices de poluição.

A bacia do Piabanha destaca-se, também, pelo uso industrial (mais de 50 indústrias de alto potencial poluidor) e pelo uso agrícola, co-responsáveis pela erosão dos solos e 
degradação das águas, juntamente com o uso urbano. Em geral, as áreas cultivadas se localizam nas margens dos rios e córregos e encostas, ocupando inclusive áreas de preservação permanente (APPs). Nessas áreas nota-se o uso abusivo de agrotóxicos.

O nível de ocupação e a intensidade de uso das terras e das águas da bacia do rio Piabanha situam-na entre as sub-bacias do Paraíba do Sul de alta prioridade para a realização de ações de proteção e recuperação de florestas, solos e águas, sendo recomendadas medidas rigorosas de restrição de uso, especialmente no curso superior do rio Piabanha e de seu afluente Preto, que devem receber prioridade máxima na proteção das florestas, na recuperação de áreas degradadas, no planejamento e controle do parcelamento do solo urbano e dos usos da água, em geral, e do uso agrícola em especial (COPPE-LABHID, 2002).

\section{Metodologia}

No início do projeto, para a escolha das bacias e locação da rede hidrometeorológica automática proposta, foram elaboradas as bases digitais preliminares do Projeto EIBEX, cartográfica e temática, utilizando-se o acervo de estudos existentes para a bacia.

Foram identificados os locais de interesse para instalação dos experimentos de acordo com os objetivos da pesquisa. A bacia representativa corresponde à área de drenagem do Rio Piabanha, tendo como seção de controle a estação Pedro do Rio. Dentro desta área foram definidas três bacias experimentais, com diferentes usos do solo, área de mata Atlântica preservada, área de uso agrícola predominante e área urbana. Os detalhes da seleção das bacias e instalação das estações integrantes do projeto podem ser encontrados em MascarenhasS (2007), vale ressaltar que as estações referentes à bacia preservada ainda não foram instaladas. A Figura 2 apresenta a bacia do rio Piabanha com a definição das bacias representativa e experimentais e dos rios principais.

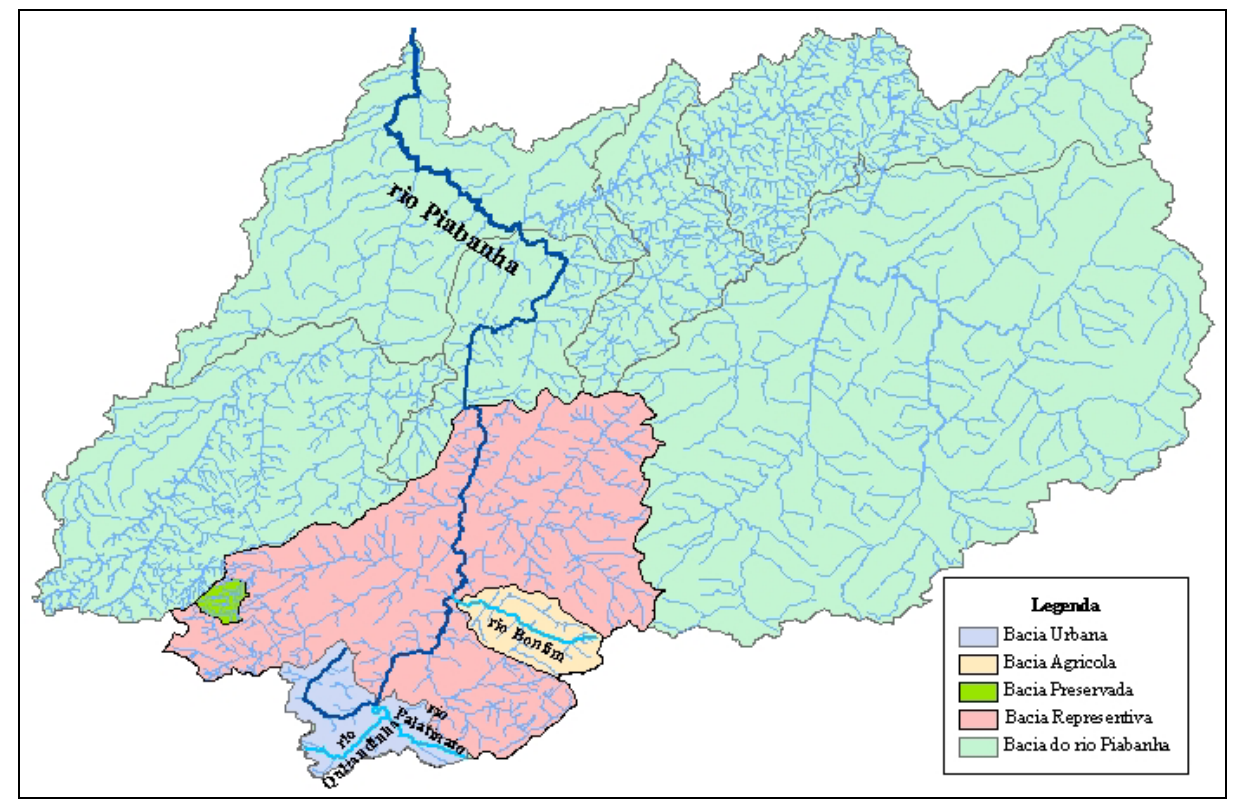

Figuras 2. Bacia do rio Piabanha com a definição das bacias experimentais e representativa.

De acordo com a localização das bacias experimentais e do objetivo dos estudos propostos, foram definidas as estações de monitoramento do projeto, que contam convencional (pluviômetro e/ou seção de réguas) e automático de registro de chuva e/ou nível. A Tabela 1 e a Figura 3 apresentam parte da rede hidrometeorológica atualmente operada pela CPRM e utilizada este estudo. 
Tabela 1. Relação das estações da Bacia Representativa do Rio Piabanha operadas pela CPRM.

\begin{tabular}{|c|c|c|c|c|c|c|}
\hline ESTAÇÃO & Código FLU & Código PLU & CURSO D'ÁGUA & $\begin{array}{c}\text { BACIA } \\
\text { EXPERIMENTAL }\end{array}$ & LATITUDE & LONGITUDE \\
\hline Parque Petrópolis & 58400250 & 02243302 & Rio Quitandinha & Urbana & $22^{\circ} 24^{\prime} 19^{\prime \prime}$ & $43^{\circ} 08^{\prime} 00^{\prime \prime}$ \\
\hline Esperança & 58400010 & 02243285 & Rio Piabanha & Urbana & $22^{\circ} 30^{\prime} 39^{\prime \prime}$ & $43^{\circ} 12^{\prime} 37^{\prime \prime}$ \\
\hline Liceu & 58400050 & 02243288 & Rio Piabanha & Urbana & $22^{\circ} 29^{\prime} 14^{\prime \prime}$ & $43^{\circ} 10^{\prime} 38^{\prime \prime}$ \\
\hline Morin & 58400030 & 02243287 & Rio Palatinado & Urbana & $22^{\circ} 31^{\prime} 00^{\prime \prime}$ & $43^{\circ} 10^{\prime} 08^{\prime \prime}$ \\
\hline Poço Tarzan & 58400110 & 02243303 & Rio Bonfim & Agrícola & $22^{\circ} 27^{\prime} 14^{\prime \prime}$ & $43^{\circ} 06^{\prime} 28^{\prime \prime}$ \\
\hline Poço do Casinho & 58400102 & $* * * *$ & Rio Açu & Agrícola & $22^{\circ} 27^{\prime} 40^{\prime \prime}$ & $43^{\circ} 05^{\prime} 41^{\prime \prime}$ \\
\hline João Christ & 58400104 & $* * * *$ & Rio Alcobaça & Agrícola & $22^{\circ} 27^{\prime} 37^{\prime \prime}$ & $43^{\circ} 06^{\prime} 00^{\prime \prime}$ \\
\hline Campo de Aventuras & $* * * *$ & 02243301 & $* * * *$ & Agrícola & $22^{\circ} 27^{\prime} 45^{\prime \prime}$ & $43^{\circ} 05^{\prime} 30^{\prime \prime}$ \\
\hline Sítio das Nascentes & $* * * *$ & 02243291 & $* * * *$ & Agrícola & $22^{\circ} 28^{\prime} 08^{\prime \prime}$ & $43^{\circ} 06^{\prime} 10^{\prime \prime}$ \\
\hline Pedro do Rio & 58405000 & $* * * * *$ & Rio Piabanha & Limite & $22^{\circ} 19^{\prime} 56^{\prime \prime}$ & $43^{\circ} 08^{\prime} 01^{\prime \prime}$ \\
\hline
\end{tabular}

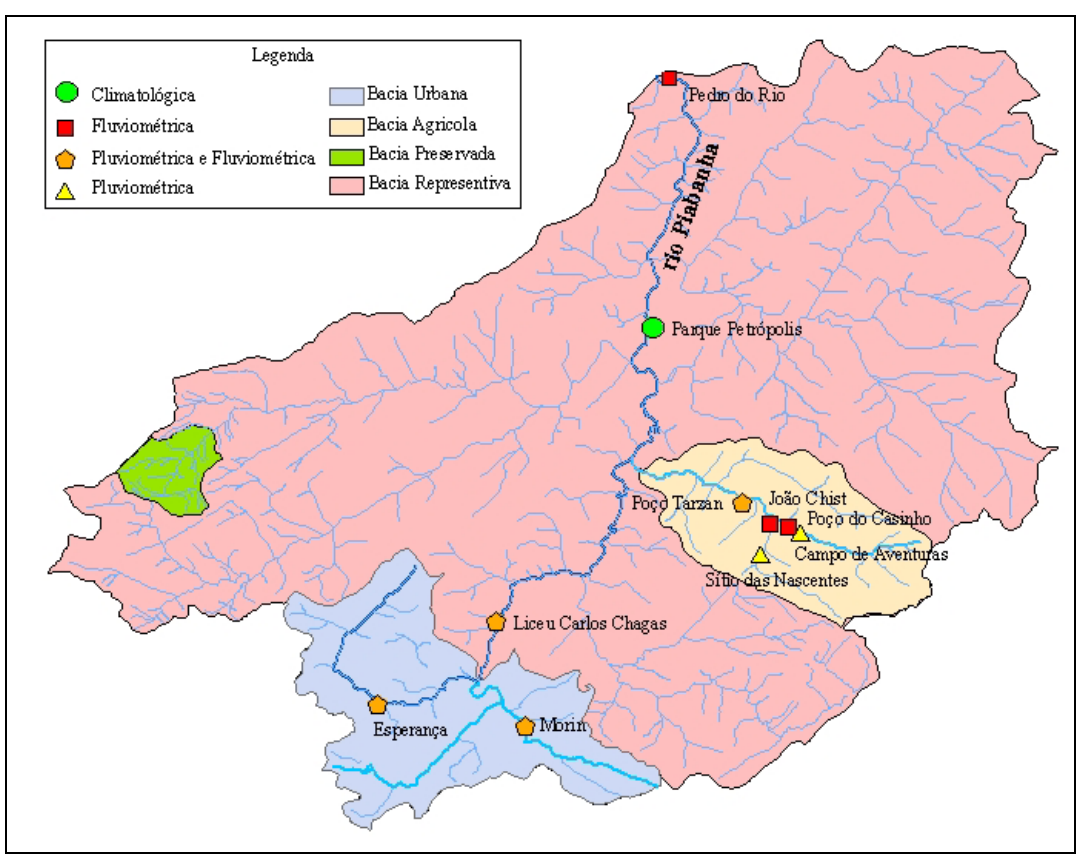

Figura 3. Bacia representativa com as bacias experimentais e as estações operadas pela CPRM e utilizadas nesse estudo.

Dentre os inúmeros estudos e atividades realizadas no âmbito do projeto, a CPRM é responsável pela manutenção das estações e levantamento e avaliação dos dados de qualidade e quantidade de água, através das ações listadas a seguir:

\section{a) Campanhas de Hidrometria}

Mensalmente são realizadas campanhas de supervisão e manutenção das estações que se encontram instaladas. Nessas campanhas, além da manutenção física das estações, são realizadas atividades, tais como: o pagamento dos observadores, recolhimento dos boletins pluviométricos e fluviométricos, medição de vazões na seção da estação, resgate dos dados armazenados nos equipamentos e a instalação de novas estações.

\section{b) Campanhas de Coletas de Amostras Qualidade de Água}

São feitas também coletas mensais de amostras e medição com equipamento de qualidade de água, para mapeamento da situação da bacia representativa. Através do equipamento são medidos quatro parâmetros: Temperatura $\left({ }^{\circ} \mathrm{C}\right)$, Condutividade Elétrica $(\mu \mathrm{S} / \mathrm{cm})$, Oxigênio Dissolvido (mg/l) e pH. 


\section{c) Modelagem de Qualidade de Água}

Os dados adquiridos através das campanhas estão sendo reunidos, analisados e consistidos para serem utilizados na modelagem de qualidade de água da bacia. Tal modelagem terá como finalidade a simulação quali-quantitativa da bacia e a avaliação das estações instaladas.

\section{d) Campanhas Eventuais}

Através de campanhas eventuais são desenvolvidas atividades complementares às anteriores e, ainda, fornecido apoio a estudos desenvolvidos na bacia por outras instituições.

\section{Resultados}

\section{a) Dados de quantidade de água}

Desde o início do projeto, foram realizadas medições de descarga líquida e a instalação de seções de réguas, de linígrafos, de pluviômetros e de pluviógrafos para a obtenção de dados de quantidade. A Tabela 2 a seguir mostra os resultados obtidos para a rede instalada, incluindo as vazões mínimas e máximas medidas no período de maio de 2007 a agosto de 2009.

Tabela 2. Relação das estações da Bacia Representaiva e resultados obtidos para medição de quantidade de água.

\begin{tabular}{|c|c|c|c|c|c|c|}
\hline ESTAÇÃO & CURSO D'ÁGUA & $\begin{array}{c}\text { MEDIÇÕES DE } \\
\text { DESCARGA } \\
\text { LÍQUIDA }\end{array}$ & $\begin{array}{c}\text { LEITURA } \\
\text { DE RÉGUA } \\
\text { (DESDE DE) }\end{array}$ & $\begin{array}{c}\text { PLUVIÔMETRO / } \\
\text { PLUVIÓGRAFO } \\
(\text { DESDE DE) }\end{array}$ & $\begin{array}{c}\text { VAZÃO } \\
\text { MÍNIMA } \\
\left(\mathrm{M}^{3} / S\right)\end{array}$ & $\begin{array}{c}\text { VAZÃO } \\
\text { MÁXIMA } \\
\left(\mathrm{M}^{3} / S\right)\end{array}$ \\
\hline Parque Petrópolis & Rio Quitandinha & 7 & agosto-07 & março-07 & 1,940 & 20,500 \\
\hline Esperança & Rio Piabanha & 6 & abril-07 & abril-07 & 0,319 & 0,593 \\
\hline Liceu & Rio Piabanha & 6 & abril-07 & abril-07 & 0,958 & 2,534 \\
\hline Morin & Rio Palatinado & 6 & abril-07 & abril-07 & 0,098 & 1,067 \\
\hline Poço Tarzan & Rio Bonfim & 7 & maio-07 & maio-07 & 0,072 & 1,001 \\
\hline Poço do Casinho & Rio Açu & 5 & outubro-07 & - & 0,009 & 0,735 \\
\hline João Christ & Rio Alcobaça & 4 & outubro-07 & - & 0,024 & 0,294 \\
\hline Campo de Aventuras & - & - & - & março-07 & - & - \\
\hline Sítio das Nascentes & - & - & - & novembro-07 & - & - \\
\hline Pedro do Rio* & Rio Piabanha & 281 & agosto-30 & janeiro-38 & 1,530 & 70,400 \\
\hline
\end{tabular}

*estação componente da Rede ANA

\section{b) Dados de qualidade de água}

Até o presente momento, foi realizada apenas uma campanha para medição da qualidade da água da bacia. Foram feitas análises de 29 parâmetros pelo LAMIN - Laboratório de Análises Minerais - da CPRM e por um laboratório particular. Nas análises efetuadas pretendeu-se correlacionar os valores obtidos com os limites dispostos na Resolução CONAMA N 357 e assim obter-se um diagnóstico preliminar da bacia. A Tabela 3 a seguir mostra os resultados obtidos para a primeira campanha de qualidade de água realizada na bacia do Rio Representativa, em agosto, com foco nas bacias de uso agrícola e de ocupação urbana a partir das análise das amostras e da medição com a sonda de qualidade de água.

Na Tabela 3 os resultados foram assinalados de cores diferentes de acordo com os limites estabelecidos pela Resolução CONAMA No 357 para as classes de uso. Sendo assim, os dados em preto correspondem a Classe 1, os em amarelo a Classe 2, os em verde a Classe 3, os em vermelho a Classe 4 e os em marrom não constam na Resolução. Para os resultados em azul não é possível definir classe de uso pois o limite de quantificação do aparelho de análise é maior que o limite da Classe 1. 
Tabela 3. Resultados obtidos para a $1^{\mathrm{a}}$ campanha realizada na bacia Representativa.

\begin{tabular}{|c|c|c|c|c|c|c|c|c|}
\hline Parâmetros (mg/l)* & \multicolumn{8}{|c|}{ Estações } \\
\hline Coleta & P. Casinho & \begin{tabular}{|l|} 
J. Christ \\
\end{tabular} & P. Tarzan & Esperança & Morin & Liceu & P. Petrópolis & P. do Rio \\
\hline Alumínio (Al) & 0,016 & 0,033 & 0,026 & 0,017 & 0,027 & 0,012 & 0,011 & 0,008 \\
\hline Antimônio (Sb) & $<0,005$ & $<0,005$ & $<0,005$ & $<0,005$ & $<0,005$ & $<0,005$ & $<0,005$ & $<0,005$ \\
\hline Arsênio (As) & $<0,008$ & $<0,008$ & $<0,008$ & $<0,008$ & $<0,008$ & $<0,008$ & $<0,008$ & $<0,008$ \\
\hline Cádmio (Cd) & $<0,002$ & $<0,002$ & $<0,002$ & $<0,002$ & $<0,002$ & $<0,002$ & $<0,002$ & $<0,002$ \\
\hline $\mathrm{CE}^{*}(\mu \mathrm{S} / \mathrm{cm})$ & 16,50 & 35,20 & 43,70 & 146,30 & 960,00 & 187,90 & 189,40 & 136,50 \\
\hline Chumbo (Pb) & $<0,010$ & $<0,010$ & $<0,010$ & $<0,010$ & $<0,010$ & $<0,010$ & $<0,010$ & $<0,010$ \\
\hline Cianeto Livre (CN) & $<0,03$ & $<0,03$ & $<0,03$ & $<0,03$ & $<0,03$ & $<0,03$ & $<0,03$ & $<0,03$ \\
\hline Cobalto (Co) & $<0,003$ & $<0,003$ & $<0,003$ & $<0,003$ & $<0,003$ & $<0,003$ & $<0,003$ & $<0,003$ \\
\hline Cobre $(\mathrm{Cu})$ & $<0,002$ & $<0,002$ & $<0,002$ & $<0,002$ & $<0,002$ & $<0,002$ & $<0,002$ & $<0,002$ \\
\hline $\begin{array}{l}\text { Coliformes Fecais* } \\
\qquad(\mathrm{NMP} / 100 \mathrm{ml})^{\#}\end{array}$ & 5.400 & 460 & 920 & $>16.000$ & $>16.000$ & 9.200 & 920 & 1.400 \\
\hline $\begin{array}{l}\text { Coliformes Totais* } \\
(\mathrm{NMP} / 100 \mathrm{ml}){ }^{\#}\end{array}$ & 5.400 & 240 & 240 & 9.200 & 5.400 & 3.500 & 240 & 240 \\
\hline Cromo $(\mathrm{Cr})$ & $<0,003$ & $<0,003$ & $<0,003$ & $<0,003$ & $<0,003$ & $<0,003$ & $<0,003$ & $<0,003$ \\
\hline $\mathrm{DBO}^{\#}$ & N.D. & N.D. & N.D. & 10,5 & 10,5 & 9,5 & 7,0 & 11,5 \\
\hline $\mathrm{DQO}^{\#}$ & N.D. & N.D. & N.D. & 37,4 & 37,3 & 33,7 & 24,8 & 40,7 \\
\hline Estanho (Sn) & $<0,010$ & $<0,010$ & $<0,010$ & $<0,010$ & $<0,010$ & $<0,010$ & $<0,010$ & $<0,010$ \\
\hline Ferro $(\mathrm{Fe})$ & 0,016 & 0,034 & 0,022 & 0,145 & 0,134 & 0,093 & 0,093 & 0,088 \\
\hline Fluoreto (F) & 0,03 & 0,04 & 0,04 & 0,08 & 0,05 & 0,10 & 0,08 & 0,07 \\
\hline Fosfato $\left(\mathrm{PO}_{4}^{-3}\right)$ & 0,40 & 1,02 & 0,92 & 4,67 & 53,11 & 6,23 & 7,33 & 5,07 \\
\hline Manganês (Mn) & $<0,007$ & $<0,007$ & $<0,007$ & 0,007 & 0,034 & $<0,007$ & $<0,007$ & $<0,007$ \\
\hline $\mathrm{NH}_{4}$ & $<0,025$ & $<0,025$ & $<0,025$ & 6,000 & 12,000 & 8,000 & 6,000 & 2,000 \\
\hline Níquel (Ni) & $<0,007$ & $<0,007$ & $<0,007$ & 0,025 & $<0,007$ & $<0,007$ & $<0,007$ & $<0,007$ \\
\hline Nitrato $\left(\mathrm{NO}_{3}{ }^{-}\right)$ & 0,98 & 3,32 & 7,12 & 1,62 & 45,49 & 3,37 & 28,39 & 13,06 \\
\hline $\mathrm{pH}$ & 6,95 & 6,86 & 6,91 & 6,80 & 7,03 & \begin{tabular}{|l|}
6,67 \\
\end{tabular} & 6,81 & 6,50 \\
\hline Prata (Ag) & $<0,003$ & $<0,003$ & $<0,003$ & $<0,003$ & $<0,003$ & $<0,003$ & $<0,003$ & $<0,003$ \\
\hline Selênio (Se) & $<0,010$ & 0,010 & $<0,010$ & $<0,010$ & 0,010 & $<0,010$ & $<0,010$ & $<0,010$ \\
\hline Sól. Susp. & $<5,0$ & $<5,0$ & $<5,0$ & $<5,0$ & $<5,0$ & $<5,0$ & $<5,0$ & $<5,0$ \\
\hline Sulfato $\left(\mathrm{SO}_{4}{ }^{-2}\right)$ & $<0,10$ & $<0,10$ & $<0,10$ & $<0,10$ & 2,21 & $<0,10$ & $<0,10$ & $<0,10$ \\
\hline $\operatorname{SVOC}^{*}(\mu \mathrm{g} / \mathrm{l})^{\#}$ & N.D. & N.D. & N.D. & N.D. & N.D. & N.D. & N.D. & N.D. \\
\hline Zinco (Zn) & $<0,020$ & $<0,020$ & $<0,020$ & $<0,020$ & 0,020 & $<0,020$ & $<0,020$ & $<0,020$ \\
\hline Sonda & P. Casinho & \begin{tabular}{|l|} 
J. Christ \\
\end{tabular} & P. Tarzan & Esperança & Morin & Liceu & P. Petrópolis & P. do Rio \\
\hline Temperatura* $\left({ }^{\circ} \mathrm{C}\right)$ & 15,50 & 16,78 & 16,41 & 17,52 & 19,10 & 18,29 & 19,32 & 18,62 \\
\hline $\mathrm{CE}^{*}(\mu \mathrm{S} / \mathrm{cm})$ & 11 & 26 & 36 & 123 & 847 & 158 & 171 & 129 \\
\hline OD & 8,99 & 8,31 & 8,51 & 4,48 & 2,91 & 3,73 & 3,70 & 8,34 \\
\hline $\mathrm{pH}^{*}$ & 5,51 & 6,54 & 7,26 & 6,66 & 6,86 & 6,78 & 6,59 & 6,91 \\
\hline
\end{tabular}

* unidades diferentes de $\mathrm{mg} / \mathrm{l}$

\# parâmetros analisados por laboratório particular

Pode-se observar para os parâmetros Alumínio, Antimônio e Arsênio, que todas as estações apresentaram valores inferiores aos máximos permitidos, para as classes 1 e 2 da Resolução CONAMA $N^{\circ}$ 357. Estes valores são 0,100 mg/l, 0,005 mg/l e 0,01 mg/l, respectivamente.

Para o Cádmio e Cianeto livre (CN), todas as estações apresentaram valores menores que o limite de quantificação do método de análise utilizado, que é de 0,002e 0,03 mg/l, respectivamente, sendo estes menores do que os valores máximos para as Classes 1 e 2 estabelecidos pela Resolução CONAMA N 357. Por este motivo, nada se pode afirmar sobre a classificação dos resultados obtidos em todas as estações.

Para a Condutividade Elétrica (CE) não há valor estabelecido na Resolução CONAMA $\mathrm{N}^{\circ}$ 357. Contudo, trata-se de um parâmetro que pode ser relacionado aos Sólidos Totais 
Dissolvidos, cujo valor máximo, para a classe 3, é de $500 \mathrm{mg} / \mathrm{l}$, o que corresponde a uma CE de $781 \mu \mathrm{S} / \mathrm{cm}$. Observa-se que apenas a estação Morin apresentou valores acima deste e que os valores aferidos pelo equipamento de qualidade de água estão próximos aos analisados.

Os valores obtidos para o Chumbo foram menores que o valor máximo permitido, para as classes 1 e 2, da Resolução CONAMA N 357, que é de 0,01 mg/l.

Para o Cobalto e para o Cobre, observa-se que todas as estações apresentaram valores menores que os máximos permitidos para as classes 1 e 2 da Resolução CONAMA ํㅜ 357, que são de 0,05 mg/l e 0,009 mg/l, respectivamente.

Para Coliformes Fecais e Totais, ainda não se pode traçar um diagnóstico da bacia, visto que são necessárias, pelo menos, 6 coletas ao longo de 1 ano, onde os valores limites não poderão ser excedidos no mínimo em $80 \%$ das amostras. Contudo, pode-se notar que os valores obtidos para estas estações são extremamente elevados, comparado-os aos limites da Resolução CONAMA No 357, que é de $200 \mathrm{NMP} / 100 \mathrm{ml}$, para a classe 1 , de 1.000 $\mathrm{NMP} / 100 \mathrm{ml}$ para a classe 2 e de $2.500 \mathrm{NMP} / 100 \mathrm{ml}$ para a classe 3. Desta forma, as estações João Christ, Parque Petrópolis e Poço Tarzan situam-se na classe 2 para ambos os parâmetros, Pedro do Rio situa-se na classe 3 para Coliforme Fecal e na classe 2 para Coliforme Total, e as demais estações situam-se na classe 4, para ambos os parâmetros.

Para o Cromo, observa-se que todas as estações apresentaram valores menores que 0,003 mg/l. Este valor é menor que o máximo permitido de acordo com a Resolução CONAMA N ${ }^{\circ}$ 357, que é de $0,05 \mathrm{mg} / \mathrm{l}$, para as classes 1 e 2 .

Os valores máximos permitidos para a DBO, para as classes 1, 2 e 3 são, respectivamente, 3,0 mg/l, 5,0 mg/l e 10,0 mg/l. Desta forma, as estações João Christ, Poço do Casinho e Poço Tarzan situam-se na classe 1, as estações Parque Petrópolis e Liceu na classe 2 e as estações Esperança, Morin e Pedro do Rio na classe 3.

Para a DQO e para o Estanho não há valores estabelecidos na Resolução CONAMA Nº 357. Contudo, pode-se notar que a DQO é cerca de 3 a 4 vezes maior que a DBO nas estações monitoradas.

Os valores obtidos para o Ferro e Fluoreto, foram inferiores ao máximo permitido pela Resolução CONAMA N 357, que é de $0,300 \mathrm{mg} / \mathrm{l}$ e $1,40 \mathrm{mg} / \mathrm{l}$, respectivamente, para as classes 1 e 2. Para o Manganês, os valores obtidos para todas as estações foram inferiores ao limite estabelecido pela Resolução, que é de $0,100 \mathrm{mg} / \mathrm{l}$, para as classes 1 e 2 .

Para o Nitrogênio Amoniacal Total $\left(\mathrm{NH}_{4}\right)$ as estações João Christ, Pedro do Rio, Poço do Casinho e Poço Tarzan apresentaram valores menores que 3,700 mg/l, limite máximo para as classes 1 e 2 da Resolução CONAMA N 357. As demais estações apresentaram valores menores que $13,300 \mathrm{mg} / \mathrm{l}$, limite da classe 3 . Os resultados obtidos foram relacionados aos valores referenciados a um $\mathrm{pH}$ menor que 7,5, caso de todas as estações.

Para o Níquel, os valores obtidos para todas as estações foram menores ou iguais ao limite da Resolução CONAMA N 357, para as classes 1 e 2, que é de 0,025 mg/l.

Para o Nitrato, as estações Esperança, João Christ, Liceu, Poço do Casinho e Poço Tarzan apresentaram valores menores que 10,0 mg/l, limite da Resolução CONAMA N 357, para as classes 1, 2, 3 e 4. As demais estações apresentaram valores superiores a este, com destaque para Morin e Parque Petrópolis, que apresentaram valores quase 5 e 3 vezes superior que o limite, respectivamente.

Para o pH, todas as estações apresentaram valores dentro da faixa estabelecida pela Resolução CONAMA N 357, que é entre 6,0 e 9,0, para todas as classes, nas análises das amostras e através do equipamento de qualidade de água, com valores bem próximos.

Para os parâmetros Prata e Selênio, os valores obtidos para todas as estações foram inferiores ou iguais aos limites estabelecidos pela Resolução CONAMA $\mathrm{N}^{\circ}$ 357, para as classes 1 e 2, que são de 0,01 mg/l. Para o Sulfato, todas as estações apresentaram valores 
bem menores que o limite estabelecido pela Resolução CONAMA $N^{\circ} 357$, que é de 250,0 $\mathrm{mg} / \mathrm{l}$ para as classes 1, 2, 3 e 4 .

Para SVOC (Pesticidas Organo-clorados), não houve detecção em nenhuma das estações das substâncias monitoradas. São elas: Alfa-BHC, Beta-BHC, Gama-BHC (Lindano), DeltaBHC, Heptachlor, Aldrin, Epoxy Heptachlor, Endosulfan 1, 4,4-DDE (p,p-DDE), Dieldrin, Endrin, Endosulfan 2, 4,4-DDD (p,p-DDD), Endrin aldeído, Endosulfan sulfate, 4,4-DDT (p,p-DDT), Endrin Ketone, Metoxichlor, Alfa-clordano, Gama-clordano e Toxafeno.

Para o Zinco, todas as estações apresentaram valores inferiores ao limite estabelecido pela Resolução CONAMA N 357, que é de $0,18 \mathrm{mg} / \mathrm{l}$, para as classes 1 e 2 .

Para o Oxigênio Dissolvido as estações da bacia de uso agrícola e Pedro do rio apresentaram-se dentro da Classe 1 da Resolução CONAMA N 357, cujo o limite inferior é 6 mg/l. Já a estação de Esperança situou-se na Classe 3, cujo limite inferior é 3mg/l e as demaisas situaram-se na classe 4 cujo limite inferior é $2 \mathrm{mg} / \mathrm{l}$,

\section{Conclusões e Recomendações}

Os resultados apresentados anteriormente, ainda que iniciais, já possibilitam um diagnóstico preliminar da quantidade e da qualidade da água.

Inicialmente, o aspecto quantitativo foi priorizado para a obtenção de séries históricas de dados de medição de descarga, nível e chuva, que possibilitarão, dentre outros, a construção de curvas-chaves, para o cálculo de vazão a ser utilizada em outros estudos de interesse da bacia. Por exemplo, a definição das cargas dos poluentes em cada uma das estações e estudos de regionalização de vazões.

Com relação à qualidade da água, pode-se ressaltar alguns aspectos interessantes. Os resultados obtidos expressam a grande contaminação por esgotos domésticos na área urbana, verificados pelos baixos valores de OD e altos índices de coliformes fecais e totais, $\mathrm{NH}_{4}$, Nitrato e DBO. Nota-se, no caso deste, a contaminação originada no centro de Petrópolis (Estações Esperança e Liceu), a seguir uma leve recuperação (Estação Parque Petrópolis) e, por último, uma degradação proveniente dos distritos de Corrêas e Itaipava (Estação Pedro do Rio), ressaltando a necessidade de tratamento dos efluentes domésticos na região.

Em geral, pôde-se observar pouca contaminação por metais e não foi detectado nenhum tipo de organo-clorado da lista de análise, mesmo na bacia de uso agrícola, onde são utilizados agrotóxicos. Desta forma, para as próximas coletas serão incluídos dois tipos de pesticidas, organo-fosforados e carbamatos.

A primeira coleta realizada foi feita em período seco. Há a necessidade de realização de campanhas em períodos distintos do ano, ao longo do ano hidrológico, para um diagnóstico mais preciso da bacia. Para isto, é necessário a continuidade das campanhas para medição de quantidade e qualidade de água, que possibilitarão estudos mais aprofundados da bacia, como modelagem hidrológica e de qualidade de água.

\section{Referências:}

Araújo, L. M. N.; Morais, A.; Villas-Boas, M.D. et al Estudos Integrados de Bacias Experimentais Parametrização Hidrológica na Gestão de Recursos Hídricos da Bacia do Rio Piabanha. In: XVII Simpósio Brasileiro de Recursos Hídricos, 11., 2007, São Paulo. Anais... CD-ROM

LABHID COPPE/UFRJ (2002). "Propostas para a Criação de Áreas Sujeitas a Restrição de Uso, com vistas à Proteção dos Recursos Hídricos”. Elaborado como parte dos documentos que compõem o Plano de Recursos Hídricos da Bacia do rio Paraíba do Sul, ANA, LabHid COPPE/UFRJ, Fundação COPPETEC.

Mascarenhas, F. C. B. Projeto - EIBEX-I Estudos Integrados de Bacias Experimentais - Parametrização Hidrológica na Gestão de Recursos Hídricos das Bacias da Região Serrana do Rio de Janeiro. Rio de Janeiro: MCT/FINEP/CT-HIDRO, 2007. 72 p. 